\title{
Fabrication and Characterization of High-Sensitivity Underwater Acoustic Multimedia Communication Devices with Thick Composite PZT Films
}

\author{
Jeng-Cheng Liu, ${ }^{1}$ Yuang-Tung Cheng, ${ }^{1}$ Sheng-Yun Ho, ${ }^{2}$ \\ Hsien-Sen Hung, ${ }^{1}$ and Shun-Hsyung Chang $^{3}$ \\ ${ }^{1}$ Department of Electrical Engineering, National Taiwan Ocean University, No. 2, Peining Rd., Keelung 20224, Taiwan \\ ${ }^{2}$ Department of Electronic Engineering, Hwa-Hsia University of Technology, No. 111, Gongzhuan Rd., Zhonghe Dist., \\ New Taipei City 23568, Taiwan \\ ${ }^{3}$ Department of Microelectronic Engineering, National Kaohsiung Marine University, No. 142, Haijhuan Rd., \\ Kaohsiung 81143, Taiwan
}

Correspondence should be addressed to Shun-Hsyung Chang; stephenshchangntou@gmail.com

Received 20 February 2017; Revised 9 April 2017; Accepted 10 April 2017; Published 14 May 2017

Academic Editor: Zubair Ahmad

Copyright (C) 2017 Jeng-Cheng Liu et al. This is an open access article distributed under the Creative Commons Attribution License, which permits unrestricted use, distribution, and reproduction in any medium, provided the original work is properly cited.

\begin{abstract}
This paper presents a high-sensitivity hydrophone fabricated with a Microelectromechanical Systems (MEMS) process using epitaxial thin films grown on silicon wafers. The evaluated resonant frequency was calculated through finite-element analysis (FEA). The hydrophone was designed, fabricated, and characterized by different measurements performed in a water tank, by using a pulsed sound technique with a sensitivity of $-190 \mathrm{~dB} \pm 2 \mathrm{~dB}$ for frequencies in the range $50-500 \mathrm{~Hz}$. These results indicate the high-performance miniaturized acoustic devices, which can impact a variety of technological applications.
\end{abstract}

\section{Introduction}

Acoustic technologies are widely used for underwater survey evaluations, especially in sonar systems. The applications of hydrophones have been restricted by the sensitivity, desired resonance frequency, and device shape. Hydrophone miniaturization has been a subject of study in recent years [13]. However, miniaturization of most conventional acoustic transducers is limited to low resolution, less sensitivity, and high impedance at low frequencies and the performance curve is no longer understandable [4] Micromachined ultrasonic transducers which integrate piezoelectric layers on silicon substrate offer an excellent solution to overcoming the shortcomings of conventional acoustic transducers [57]. Furthermore, a significant reduction of the hydrophone's physical dimensions will not easily react to acoustic diffraction, which is advantageous for accurate measurements.

Piezoelectric thin films have attracted attention because of their appropriate thickness in obtaining the desired frequency response characteristics of the ultrasonic transducers. With the desire for large piezoelectric coefficients, thick lead zirconate titanate (PZT) film is the best candidate material for use in ultrasonic transducers for high-resolution imaging [8]. By using a Microelectromechanical Systems (MEMS) fabrication process for integrated circuits (ICs) $[9,10]$, the ultrasonic hydrophone allows the combination of signal and image processing circuits, such as amplifier and filter circuits, allowing sensitivity to be improved. The piezoelectric micromachined ultrasonic transducers (pMUT), which are driven by PZT film pMUTs, have a lower operating voltage and higher transmission power [11, 12].

In this paper, we have prepared an epitaxial PZT diaphragm structure for underwater hydrophone on silicon substrates and used a finite-element analysis (FEA) to estimate vibration parameters of the hydrophone. As a result of the FEA, an improved hydrophone was fabricated and evaluated. This paper proposed and fabricated pMUT using a diaphragm structure for underwater acoustics applications 
in the frequency band from $0.1 \mathrm{~Hz}$ up to $100 \mathrm{kHz}$, which is the frequency range of interest for underwater sensing applications [13].

We describe the growth and the structural characterization of PZT thin films grown on silicon wafers through oxide transition layers. In order to obtain high-quality thin films on silicon, it is essential to develop a controlled growth process suitable for the piezoelectric layer. As a result, during the design and fabrication of acoustic devices, an optimized thin-film thickness can be utilized to control the frequency response characteristics of the hydrophone. This paper investigates the properties of diaphragm for the hydrophone applications in water, and to achieve this objective, the sensitivity of hydrophones is measured and the characterization of the mechanical properties are calculated. The hydrophone performed in a water tank is used as a pulsed sound technique for calibration. Results on acoustical sensitivity measurements, directivity, and sound pressure level are discussed.

\section{Device Design}

The acoustic device is a piezoelectric transducer used to detect underwater sounds and convert the mechanical signals of low frequency acoustic waves into electrical signals. Thus, the hydrophone performance is primarily evaluated in terms of frequency range, sensitivity, and sound pressure level. According to the small deflection theories of plates, miniature high sensitivity of the hydrophone is achieved. The hydrophone sensing diaphragm relates the thin films thickness of piezoelectric material to the applied hydrostatic stress and is a useful parameter for evaluating device dimensions. Hydrophone is measured by the voltage that is produced per unit of hydrostatic pressure. If the underwater hydrophone sensing diaphragm is designed in a circular shape with a large initial tensile stress, the mechanical sensitivity $[\mathrm{V} / \mathrm{Pa}]$ of the underwater microphone can be expressed as [17-19]

$$
S=\frac{a^{2}}{8 \delta t},
$$

where $a$ is the hydrophones diaphragm radius, $\delta$ is the hydrophone's diaphragm residual stress, and $t$ is the hydrophones diaphragm thickness. According to (1), hydrophones with thinner diaphragms have higher sensitivity and large areas of the diaphragm can improve the mechanical sensitivity of the acoustic film. In addition, the opening of the slot gap in the sensing diaphragm can reduce the residual stress in the diaphragm and increase the mechanical sensitivity of the hydrophone. But the slot gap design is prone to parasitic capacitance and will reduce the hydrophone's electrical sensitivity. Therefore, we designed a composite diaphragm structure to adjust the stress of the acoustic sensing diaphragm. By using the tensile stress and compressive stress between different stress-producing materials, a stresscancellation effect can be achieved, reducing the stress of the acoustic sensing composite diaphragm.

Diaphragm thickness and dimensions can affect sensitivity. In the sensitivity suitable for hydrophone applications, the small deflection theories of plates are analyzed. The most effective approach to analysis can be found for the pressuredeflection relationships of plates made of isotropic, homogeneous, linearly elastic materials [20]. In order to optimize the microfabrication process, the hydrophones of the diaphragms are evaluated with simple geometrical shapes such as squares, rectangles, and circulars. These hydrophones of diaphragms research showed that the bimorph most easily adapts to thin-film fabrication and micromachining. In this paper, we report our efforts to develop circular bimorphs with highperformance miniaturized hydrophone systems, thus achieving a better theoretical sensitivity than the reported ones. In a simple circular bimorph under small deflection, we calculated radial $\left(\varepsilon_{r}\right)$ and circumferential $\left(\varepsilon_{\theta}\right)$ strain with respect to the applied pressure by the following equation [20-23]:

$$
\begin{aligned}
& \varepsilon_{r}=\frac{-3 p a^{2}\left(1-v^{2}\right)}{8 E t^{2}}\left(1-\frac{3 r^{2}}{a^{2}}\right), \\
& \varepsilon_{\theta}=\frac{-3 p a^{2}\left(1-v^{2}\right)}{8 E t^{2}}\left(1-\frac{r^{2}}{a^{2}}\right),
\end{aligned}
$$

where $p$ is the applied pressure, $E$ is Young's modulus, and $v$ is Poisson's ratio. Diaphragm thickness is represented as $t$, diaphragm radius is represented as $a$, and $r$ is the calculated point radius. By studying most of the research concerning acoustic diaphragms, important conclusions can be drawn about the effects of the circular bimorph and water loading. It is known that the resonant frequency (work frequency) of a clamped edge circular plate can be well estimated using the following equation [20-23]:

$$
f=0.5 \frac{t}{a^{2}} \sqrt{\frac{E}{\rho}},
$$

where $\rho$ is the density of the diaphragm. According to (3), the resonance frequency is proportional to the diaphragm thickness, which concurs well with the FEA results. The circular bimorph is precisely defined by the properties of process; thus, we can obtain acoustic diaphragms quite similar to our designed ones. In the simulation, the geometrical sizes of the thin-film thickness are kept the same as in the device design.

Figure 1(a) is the schematic structure of our proposed circular shape acoustic device in the MEMS diaphragm hydrophone. The calculations were performed for $\mathrm{SiO}_{2} / \mathrm{top}$ electrode/PZT/ZnO/bottom electrode $/ \mathrm{SiO}_{2} / \mathrm{Si}$ heterojunction structure with a spherical air gap. The surface of the developed hydrophone is covered with a polyimide to protection against water. Figure $1(\mathrm{~b})$ shows a schematic of the fabricated diaphragm hydrophone array with $8 \times 8$ elements. These elements are adopted through interconnects to allow individual addressing of each element in a constrained space. The perforation in the two-dimensional structure is similar to the porosity in the 3D structures; however, the real-time 3D imaging uses a fabricated hydrophone matrix array integrated device in which the electrodes of the hydrophone elements are led to the back surface of the hydrophone substrate. The transmission and reception characteristics of the hydrophone were investigated using the impulse response in the $200 \mathrm{~Hz}$ frequency band. It was considered axial symmetric domain 


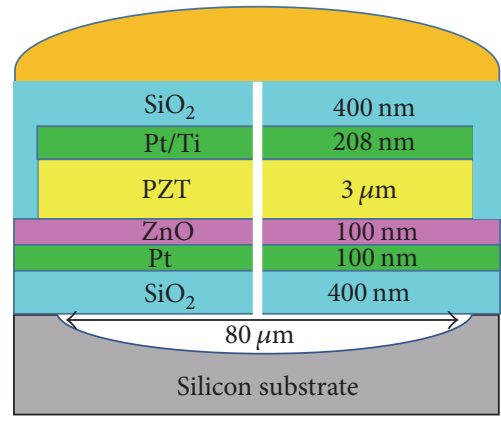

(a)

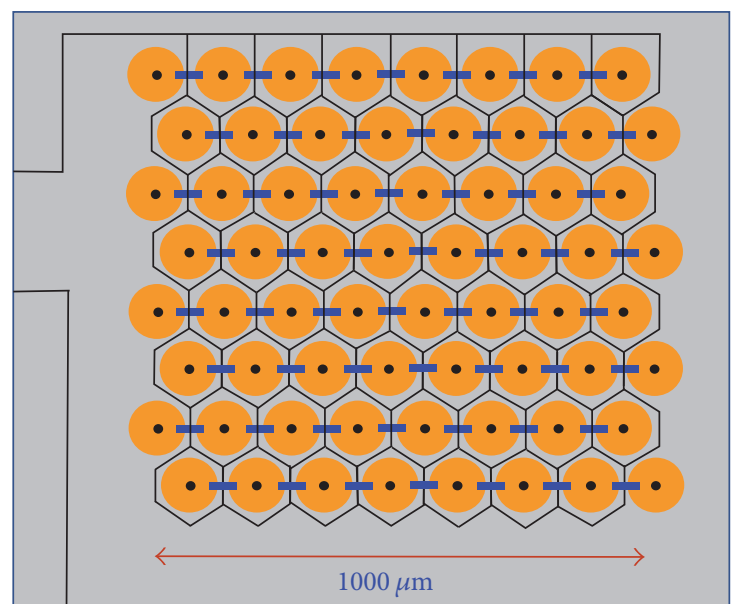

(b)

Figure 1: (a) Schematic cross section illustration of hydrophone using epitaxial $\mathrm{SiO}_{2} /$ top electrode $/ \mathrm{PZT} / \mathrm{ZnO} / \mathrm{bottom}$ electrode/SiO $/ 2 / \mathrm{Si}$ heterojunction structure. (b) Schematic of this study proposed hydrophone array with $8 \times 8$ elements.

with a diameter $100 \mu \mathrm{m}$ and length $10 \mu \mathrm{m}$. To consider the boundary condition, the edge of circular plate was fixed. The resonant frequency was evaluated as a function of the cavity diameter.

ANSYS was used for FEA, which consists of a heterojunction structure. The frequency response of electric potential generated by a circular bimorph in the whole frequency range is presented in Figure 2. When sound frequency increases from $10 \mathrm{~Hz}$ up to $100 \mathrm{kHz}$, electric voltage, generated by circular bimorph, increases from $0.001 \mathrm{~V}$ up to $0.15 \mathrm{~V}$. The general trend of growth response with increasing frequency is destroyed by the peaks associated with resonances of the hydrophone. Comparison of the three frequency response curves shows that high underwater hydrostatic pressure does not noticeably affect the sensitivity parameters of the solid design hydrophone.

\section{Experimental Procedure}

In this paper, the devices were prepared on 4-inch, singlesided polished bare (111) silicon wafers (supplied by SinoAmerican Silicon Product Corporation). The wafer was cleaned by RCA (a recipe developed by the RCA Company) procedure and dried with nitrogen gas before beginning the process. A layer of silicon dioxide $\left(\mathrm{SiO}_{2}\right)$ was first deposited on a $\mathrm{Si}$ substrate by radio frequency (RF) magnetron sputtering at room temperature. The bottom electrode Pt $100 \mathrm{~nm}$ thick and $\mathrm{ZnO} 100 \mathrm{~nm}$ thick layer were deposited using RF-magnetron sputtering system. Subsequently, piezoelectric PZT thin films $3 \mu \mathrm{m}$ in thickness were deposited by using a conventional sol-gel method. The PZT solution (with $\mathrm{Zr}$ : Ti ratio $=52: 48$ ) was deposited on the $\mathrm{ZnO}$ coated by spincoating at $3000 \mathrm{rpm}$ for 30 seconds, then baked at $350^{\circ} \mathrm{C}$ for 60 seconds on a hot plate, and next crystallized at $600^{\circ} \mathrm{C}$ for 5 minutes for the thin films by using rapid thermal annealing (RTA). Each layer is approximately $100 \mathrm{~nm}$ thick. The PZT films were fabricated by repeating this procedure

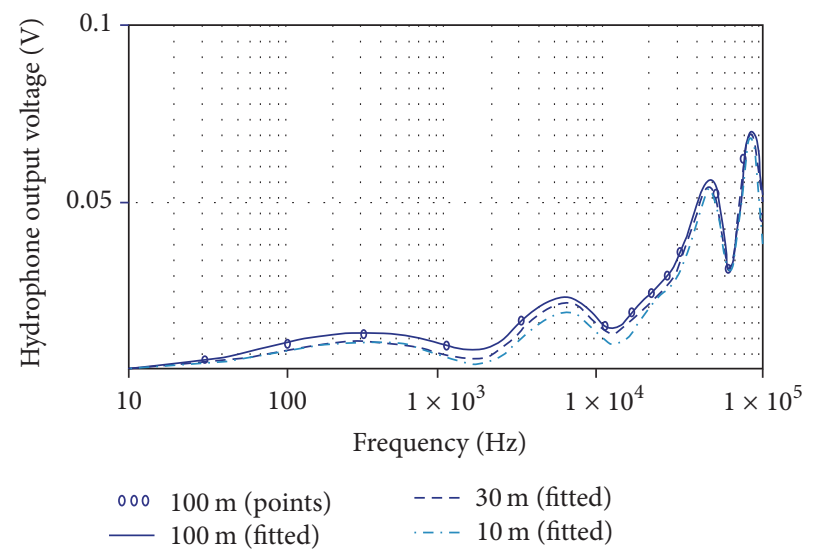

FIGURE 2: Simulation results showing the frequency response of electric potential generated by circular bimorph.

to achieve the desired thickness. The top electrode (titanium $8 \mathrm{~nm} /$ platinum $200 \mathrm{~nm}$ ) was deposited using multitarget RFmagnetron sputtering. $\mathrm{A} \mathrm{SiO}_{2}$ film with $400 \mathrm{~nm}$ in thickness was formed by RF-magnetron sputtering under metal wiring. The stack of the $\mathrm{SiO}_{2} / \mathrm{Pt} / \mathrm{Ti} / \mathrm{PZT} / \mathrm{ZnO} / \mathrm{Pt} / \mathrm{SiO}_{2}$ was etched to expose the surface of the $\mathrm{Si}$ substrate by reactive ion etching (RIE). Then, bare Si removed native oxide by carbon tetrafluoride $\left(\mathrm{CF}_{4}\right)$ etching to ensure cavities were symmetrical. Subsequently, Si substrate below the diaphragm area was etched by Xenon difluoride $\left(\mathrm{XeF}_{2}\right)$ gas from the top side of the device. The etching rate was about $10-15 \mu \mathrm{m} /$ hour, and etching was isotropic. A spherical cavity of $100 \mu \mathrm{m}$ diameter was formed below the PZT/metal films after this etching process. After $\mathrm{XeF}_{2}$ etching, bonding wires were covered with epoxy to ensure that the device can be immersed in water.

The morphology of the films was characterized with high-resolution field emission scanning electron microscopy 


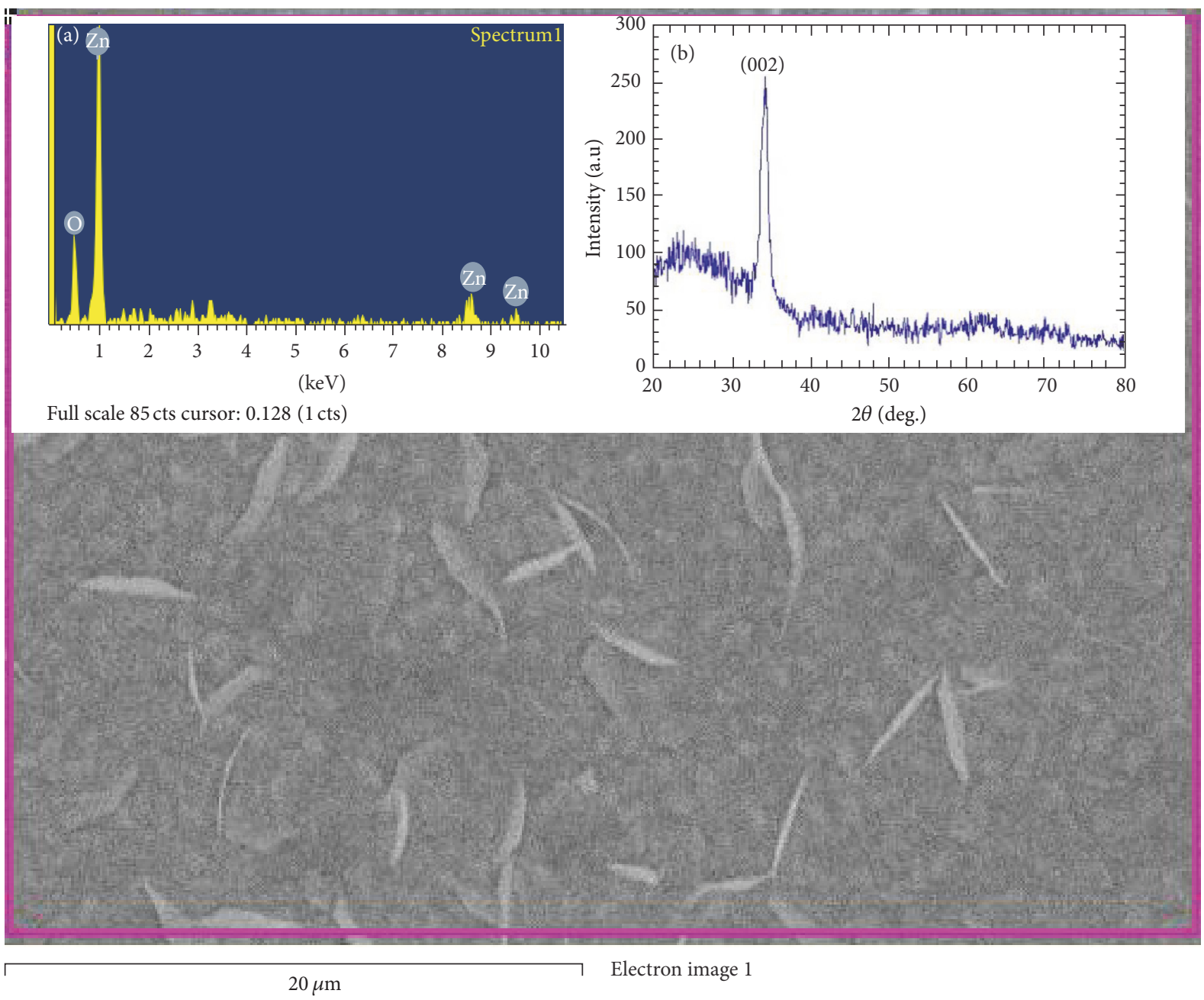

Figure 3: SEM image of the $\mathrm{ZnO}$ film grown on $\mathrm{Pt} / \mathrm{SiO}_{2} / \mathrm{Si}$. (a) The left inset is the EDS spectrum. (b) The right inset shows the XRD patterns of the $\mathrm{ZnO}$ films.

(FESEM; JEOL-6330, Japan). Energy dispersive X-ray spectroscopy (EDS) measured by a field emission scanning electron microscopy (FESEM) attachment was used to characterize the elemental composition of the thin films. The heterojunction structure of the thin films was examined using an X-ray diffractometer (XRD, Bruker D8 Discover) with $\mathrm{CuK} \alpha$ radiation $(\lambda=0.154060 \mathrm{~nm})$. Patterns were recorded at a rate of $0.1^{\circ} /$ second in the $2 \theta$ range of $20^{\circ}$ to $80^{\circ}$.

\section{Results and Discussion}

Figure 3 shows the FESEM image of the $\mathrm{ZnO}$ thin film. It can be seen that homogeneous size with an average length of $\sim 50 \mathrm{~nm}$ was grown on the Pt. The film was randomly oriented because the $\mathrm{ZnO}$ film was disordered. It was likely that the crystallization and growth of the $\mathrm{ZnO}$ film was significantly influenced by the Pt film. The inset in Figure 3 lift side is the EDS spectrum of the $\mathrm{ZnO}$ film, where, except for the peaks corresponding to $\mathrm{Zn}$ and $\mathrm{O}$, no other peaks were observed in the test range. The contents of $\mathrm{Zn}$ and $\mathrm{O}$ are determined to be $44.75 \%$ and $55.25 \%$, respectively, which is the chemical composition that matches the stoichiometry. Figure 3 on the right side in the insert shows the XRD patterns of the $\mathrm{ZnO}$ film at a diffraction angle of $34.3^{\circ}$. As shown in Figure 3 on the right side in the insert, the diffraction intensity of the $\mathrm{ZnO}$ (002) peak is higher than those of the other peaks. Based on the XRD analysis, the processing conditions were optimized the $\mathrm{ZnO}$ and $\mathrm{Pt}$ films with the best crystallinity, texture, and uniformity that could be obtained. Meanwhile, $\mathrm{Pt}$ is hardly oxidized and $\mathrm{SiO}_{2}$ thin film is used as a buffer layer of Pt on the bottom electrode of the silicon wafer to improve the adhesive durability between the bottom electrode and substrate. This reveals that the $\mathrm{ZnO}$ film can promote piezoelectric characteristics. In summary, $\mathrm{Pt}$ was considered with the purpose of obtaining a better orientation of $\mathrm{ZnO}$ thin film.

Figure 4 shows an XRD pattern of a $5 \mu \mathrm{m}$ PZT (52/48) thick film deposited on the $\mathrm{ZnO}$ coat. The positions of the (100), (110), (111), (200), (210), and (211) peaks confirm that the thin films have the PZT perovskite phase. It was found that PET films have a perovskite phase with a strong (110) peak and no pyrochlore phase observed. The PZT film was likely that 


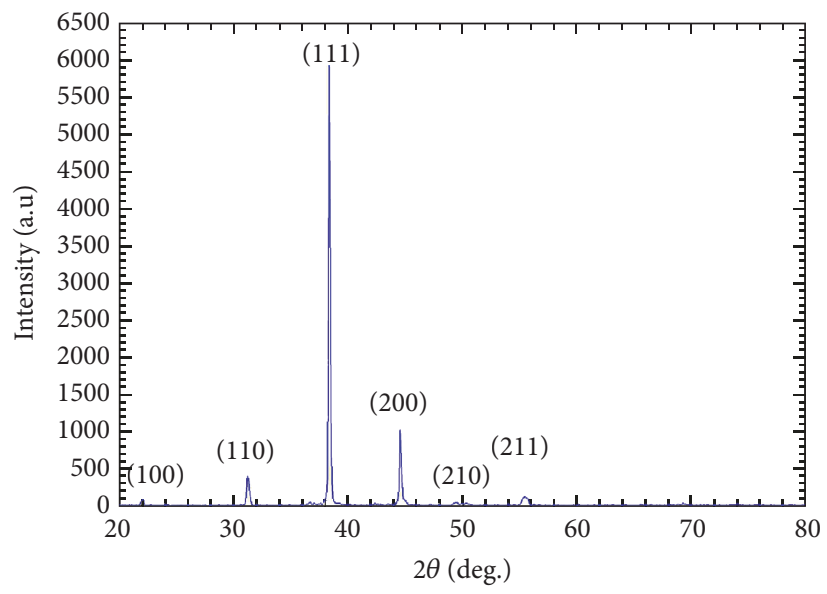

FIgUre 4: XRD results of PZT thin films on $\mathrm{ZnO} / \mathrm{Pt} / \mathrm{SiO}_{2} / \mathrm{Si}$.

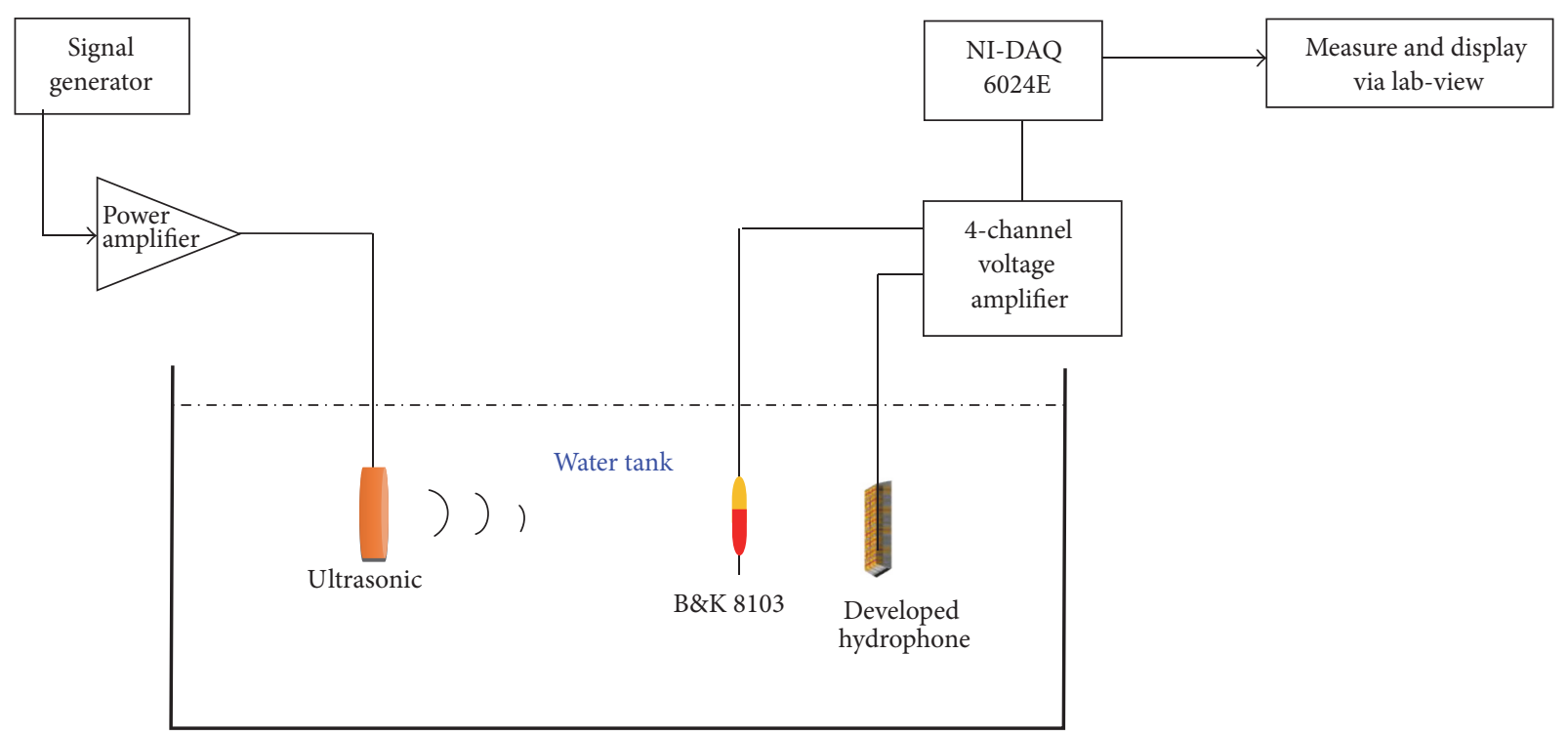

FIGURE 5: Experimental setup for measuring hydrophone sensitivity by comparison with a B\&K 8103 hydrophone.

the crystallization and growth of the PZT (52/48) film were significantly influenced by the $\mathrm{ZnO} / \mathrm{Pt} / \mathrm{SiO}_{3} / \mathrm{Si}$ film structure due to the close matching of lattice parameters.

Figure 5 shows the underwater experimental setup to measure the receiver characteristics of the hydrophone at different frequencies. A calibrated hydrophone (B\&K 8103) is used as a reference hydrophone for calibration. The developed hydrophone and the reference hydrophone are placed next to each other and are driven by an underwater signal generator. The signal generator was driven at frequencies from 50 to $500 \mathrm{~Hz}$, producing hydrostatic pressure on the developed hydrophone and the reference hydrophone. To measure the frequency response of the hydrophone, the received signals were observed using the Lab-View system (obtained by acquisition device NI-DAQ 6024E) through 4 channel amplifier. Using the reference hydrophone in Channel 1, the acoustic pressure was measured, and the signal from the developed hydrophone in Channel 2 was calibrated using the measured acoustic pressure. Ultrasonic sensitivities of the hydrophone were calculated from the generated ultrasonic sound pressure and the output signal.

Figure 6(a) shows the sensitivity of the hydrophone in response to swept frequencies in the range $50 \mathrm{~Hz}$ to $500 \mathrm{~Hz}$. The sensitivity is around $-190 \mathrm{~dB} \pm 2 \mathrm{~dB}$ (Ref. $\mathrm{V} / \mu \mathrm{Pa}$ ) in the flat region between 50 and $420 \mathrm{~Hz}$, which almost completely covers the generated frequency range of the underwater oscillatory flow disturbances. The sudden increase in level, at approximately $220 \mathrm{~Hz}$, is due to the first resonance mode of the developed hydrophone. The second deviation is within $\pm 4 \mathrm{~dB}$ near $440 \mathrm{~Hz}$. This result was anticipated, because the deviations in frequency response are attributed to the acoustic effects of the waveguide $[24,25]$. The devices operated at different frequencies with different measurement locations, showing that the hydrophone performed well. Therefore, the 


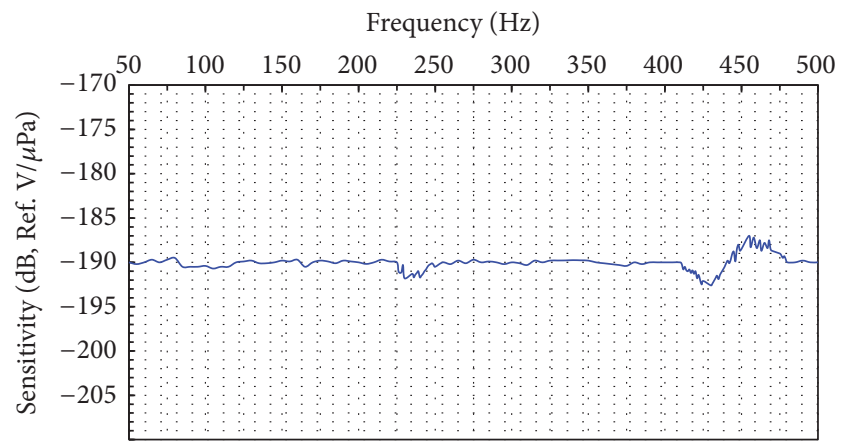

(a)

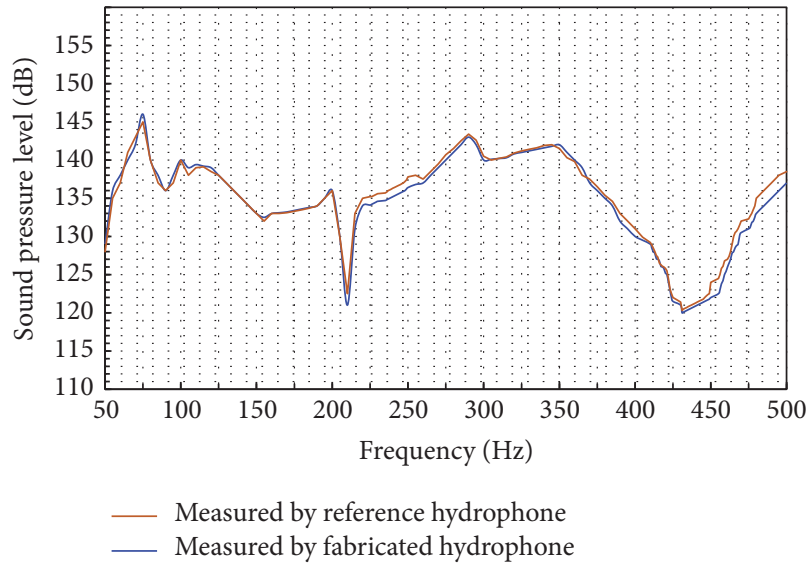

(b)

Figure 6: (a) Measured frequency-sensitivity characteristics of the developed hydrophone. (b) The sound pressure level measured results from fabricated and reference hydrophones.

TABLE 1: Details of the four hydrophones used in the comparison.

\begin{tabular}{lcccc}
\hline Manufacturer & Hydrophone type & Sensitivity dB, ref. V/ $\mu \mathrm{Pa}$ & Operation bandwidth & Reference \\
\hline Taiwan & This work & -190 & $1-500 \mathrm{~Hz}$ & \\
Brüel \& Kjær & BK-8103 & -210 & $0.1 \mathrm{~Hz}-180 \mathrm{kHz}$ & $15 \mathrm{~Hz}-120 \mathrm{kHz}$ \\
Reason. & TC-4040 & -206 & $100-500 \mathrm{kHz}$ & {$[14]$} \\
USRD & H52 & -218 & {$[15]$} & {$[16]$} \\
\hline
\end{tabular}

developed hydrophone is suitable for the intended application of underwater sensing.

Figure 6(b) shows the sound pressure level power spectral density measured at different frequencies. The sound pressure level was measured using the reference hydrophone and the developed hydrophone. In the comparison of the two datasets, sound pressure levels appeared almost identical. The admittance versus frequency curve of the hydrophone indicated two main valleys near to $210 \mathrm{~Hz}$ and $430 \mathrm{~Hz}$. This result indicates that the transducers directly received the ultrasonic signal from the fabricated hydrophone and showed the possibility of distance measurement. Overall, all the results confirmed that adjusting the frequency response by appropriately changing the structural design of the hydrophone is possible.

Three different commercial hydrophones used for the comparison are listed in Table 1. These commercial hydrophones are chosen because they are commonly in use as standard measuring underwater devices. The comparison has been exceedingly valuable, with much confidence gained in the performance of primary standards. In general, the heterojunction structure hydrophone presented in this work performs much better than most of the other hydrophones. Especially for the hydrophones reported in [14-16], those highly responsive hydrophones employ sophisticated arrays structure to further enhance the sensitivity, and the sensitivity of this work is still higher than commercial hydrophones.
Therefore, this work indicates a promising approach for optimization of underwater acoustic multimedia communication applications.

\section{Conclusion}

A high-performance silicon substrate hydrophone fabricated by a novel process was developed. The FEA was carried out in order to estimate the resonant frequency of the diaphragm transducer. From the results of the FEA using ANSYS, the resonant frequency was strongly affected by the element size. According to this result, we have demonstrated the fabrication of PZT piezoelectric hydrophone based on epitaxial thin films. PZT thin films epitaxially grown on $\mathrm{ZnO}$ with a $\mathrm{Pt}$ bottom electrode exhibit high crystalline quality and good piezoelectric properties. The MEMS process has been optimized for the grown thin layers with special emphasis on maintaining the piezoelectric properties. This simple and highly controllable process makes it possible to obtain hydrophones with high performance and lowcost mass-production. Experimental results demonstrated that the developed hydrophone has excellent acoustic characteristics such as high sensitivity, wide frequency range, and high maximum sound pressure level. The measured frequency responses are in good accordance with the acoustic model simulation. The results of all measurements confirmed that the acoustic characteristics of the hydrophone 
can be controlled as intended by adjusting its structural design.

\section{Conflicts of Interest}

The authors declare that they have no conflicts of interest.

\section{Acknowledgments}

The authors acknowledge financial support from The National Science Council of Taiwan, Taiwan, under Contract no. MOST 105-2923-E-022-001-MY3.

\section{References}

[1] X. Jin, I. Ladabaum, and B. T. Khuri-Yakub, "The microfabrication of capacitive ultrasonic transducers," Journal of Microelectromechanical Systems, vol. 7, no. 3, pp. 295-302, 1998.

[2] J. J. Bernstein, S. L. Finberg, K. Houston et al., "Micromachined high frequency ferroelectric sonar transducers," IEEE Transactions on Ultrasonics, Ferroelectrics, and Frequency Control, vol. 44, no. 5, pp. 960-969, 1997.

[3] M. Sung, K. Shin, and W. Moon, "A micro-machined hydrophone employing a piezoelectric body combined on the gate of a field-effect transistor," Sensors and Actuators, A: Physical, vol. 237, pp. 155-166, 2016.

[4] C. Koch and W. Molkenstruck, "Primary calibration of hydrophones with extended frequency range 1 to $70 \mathrm{MHZ}$ using optical interferometry," IEEE Transactions on Ultrasonics, Ferroelectrics, and Frequency Control, vol. 46, no. 5, pp. 1303-1314, 1999.

[5] C. H. Sherman and J. L. Butler, Transducers and Arrays for Underwater Sound, Springer, New York, NY, USA, 2007.

[6] M. Asadnia, A. G. P. Kottapalli, Z. Shen, J. Miao, and M. Triantafyllou, "Flexible and surface-mountable piezoelectric sensor arrays for underwater sensing in marine vehicles," IEEE Sensors Journal, vol. 13, no. 10, pp. 3918-3925, 2013.

[7] M. Lasky, R. D. Doolittle, B. D. Simmons, and S. G. Lemon, "Recent progress in towed hydrophone array research," IEEE Journal of Oceanic Engineering, vol. 29, no. 2, pp. 374-387, 2004.

[8] F. F. C. Duval, R. A. Dorey, R. W. Wright, Z. Huang, and R. W. Whatmore, "Fabrication and modeling of high-frequency PZT composite thick film membrane resonators," IEEE Transactions on Ultrasonics, Ferroelectrics, and Frequency Control, vol. 51, no. 10, pp. 1255-1261, 2004.

[9] S. Meti, K. B. Balavald, and B. G. Sheeparmatti, "MEMS piezoresistive pressure sensor: a survey," International Journal of Engineering Research and Applications, vol. 6, no. 4, part 1, pp. 23-31, 2016.

[10] Y. Qiu, J. V. Gigliotti, M. Wallace et al., "Piezoelectric micromachined ultrasound transducer (PMUT) arrays for integrated sensing, actuation and imaging," Sensors, vol. 15, no. 4, pp. 8020-8041, 2015.

[11] A. Safari and E. K. Akdoğan, Piezoelectric and Acoustic Materials for Transducer Applications, Springer, New York, NY, USA, 2008.

[12] O. C. Zienkiewicz and Y. K. K. Cheung, The finite Element Method in Structural and Continuum Mechanics, McGraw-Hill, London, UK, 1976.
[13] H. Bleckmann, Reception of Hydrodynamic Stimuli in Aquatic and Semi-Aquatic Animals, Springer-Verlag, New York, NY, USA, 1994.

[14] http://www.lthe.fr/LTHE/IMG/pdf/DocBruelKjaerHydro.pdf.

[15] http://www.teledyne-reson.com/download/hydrophone_data sheets__/TC4040-product-leaflet.pdf.

[16] http://www.navsea.navy.mil/Portals/103/Documents/NUWC_ Newport/USRD/H52.pdf.

[17] B. D. Cook, J. R. Laflin, C. F. Gaumond, and H. D. Dardy, "Alternative procedures for acquiring acousto-optic data for computerized tomographic evaluation of sound fields," The Journal of the Acoustical Society of America, vol. 68, pp. S94S95, 1980.

[18] L. Lin, H.-C. Chu, and Y.-W. Lu, "Simulation program for the sensitivity and linearity of piezoresistive pressure sensors," Journal of Microelectromechanical Systems, vol. 8, no. 4, pp. 514$522,1999$.

[19] J. C. Erskine, "Polycrystalline silicon-on-metal strain gauge transducer," IEEE Transactions on Electron Devices, vol. 30, no. 7, pp. 796-801, 1983.

[20] S. P. Timoshenko and S. Woinowsky-Krieger, Theory of Plates and Shells, McGraw-Hill, New York, NY, USA, 2nd edition, 1970.

[21] M. Goto, Y. Iguchi, K. Ono et al., "High-performance condenser microphone with single-crystalline silicon diaphragm and backplate," IEEE Sensors Journal, vol. 7, no. 1, pp. 4-9, 2007.

[22] M. Pedersen, W. Olthuis, and P. Bergveld, "High-performance condenser microphone with fully integrated CMOS amplifier and DC-DC voltage converter," Journal of Microelectromechanical Systems, vol. 7, no. 4, pp. 387-394, 1998.

[23] L. E. Kinsler, A. R. Frey, A. B. Coppens, and J. V. Sanders, Fundamentals of Acoustics, vol. 105, Wiley, New York, NY, USA, 4th edition, 2009.

[24] X. Lurton, An Introduction to Underwater Acoustics: Principles and Applications, Springer-Verlag, New York, NY, USA, 2002.

[25] I. Tolstoy and C. S. Clay, Ocean Acoustics: Theory and Experiment in Underwater Sound, McGraw-Hill, 1966. 


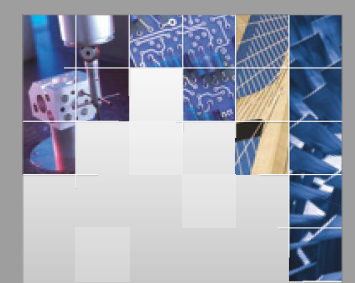

\section{Enfincering}
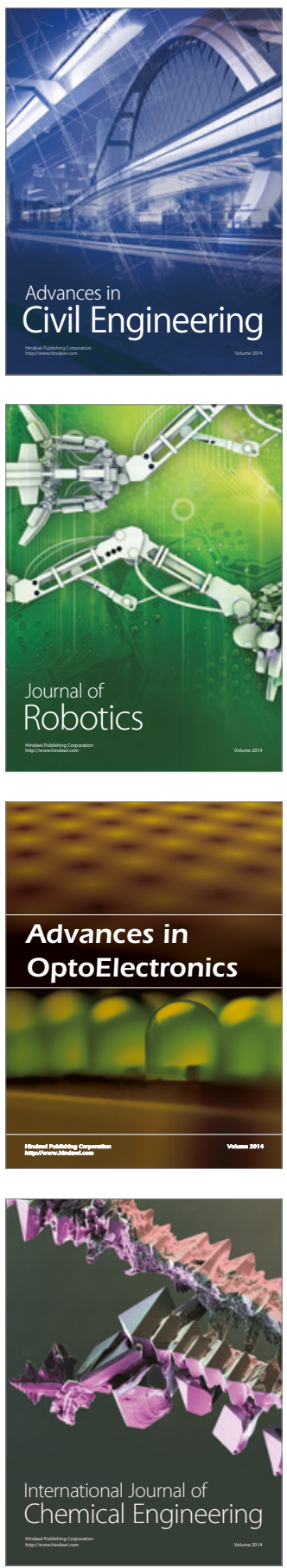

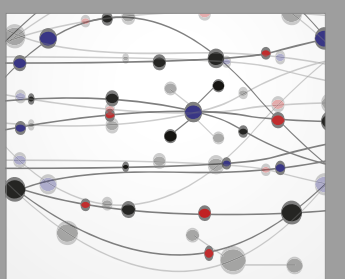

The Scientific World Journal

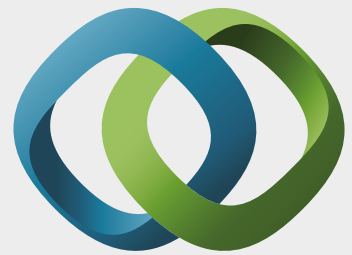

\section{Hindawi}

Submit your manuscripts at

https://www.hindawi.com
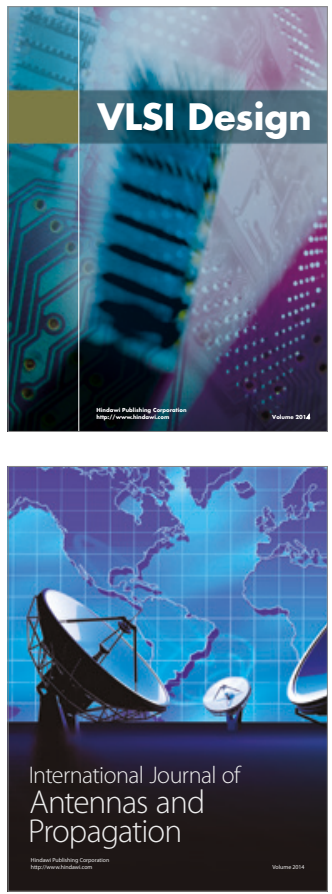

\section{Rotating}

Machinery
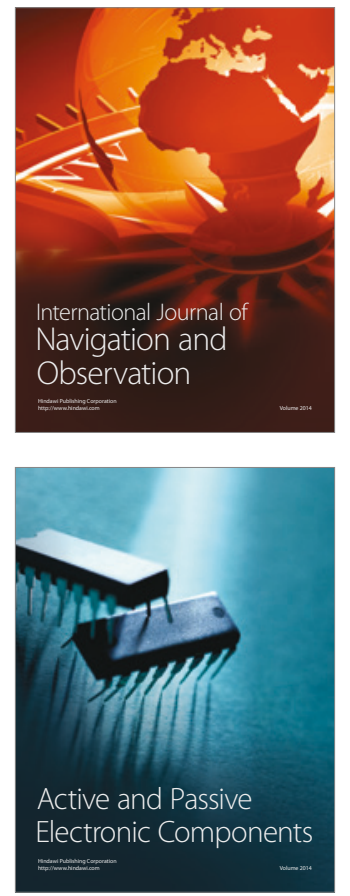
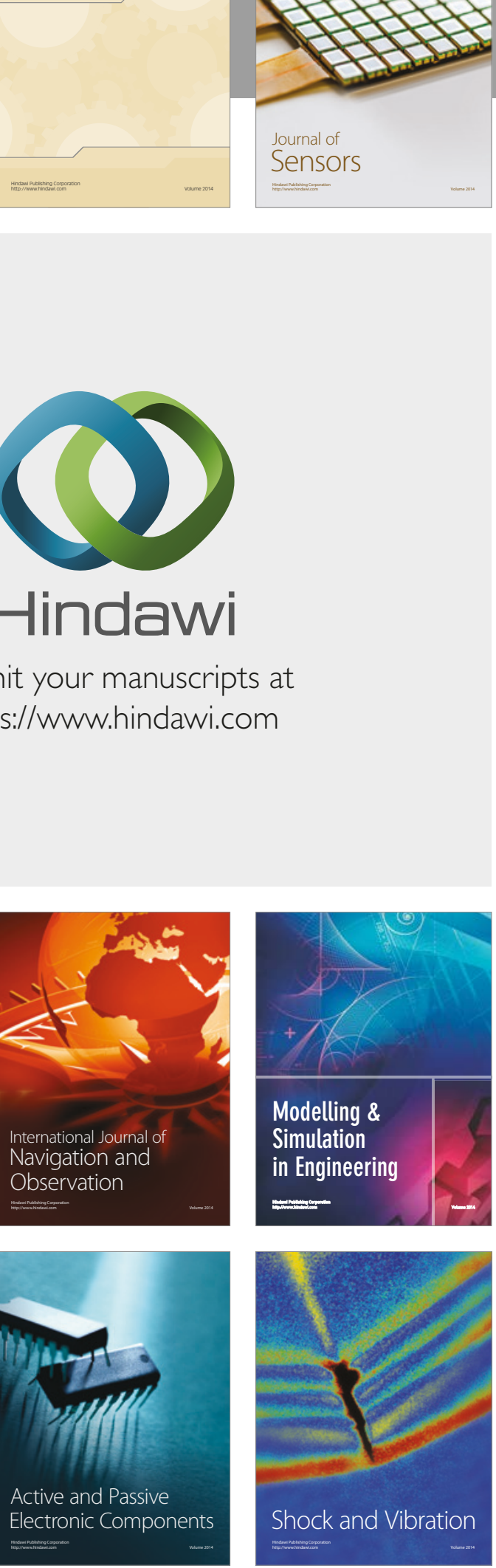
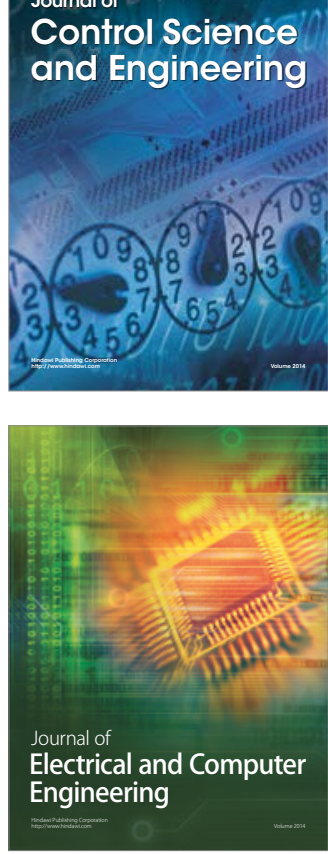

Distributed

Journal of

Control Science

and Engineering
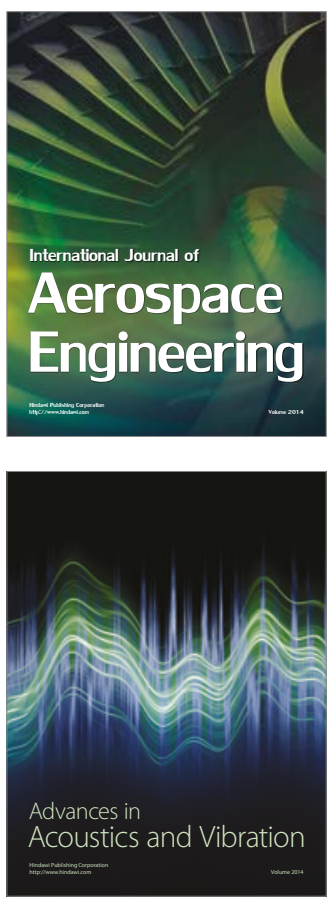

Sensor Networks 